\title{
Estimativa do teor de nitrogênio em arroz irrigado com o clorofilômetro e a cartela de cores
}

\author{
Nitrogen content estimative in flooded rice by using of chlorophyll meter and color chart
}

\author{
Elisandra Pocojeski ${ }^{I}$ Leandro Souza da Silva' ${ }^{\mathrm{II}}$ Angela da Cas Bundt ${ }^{\mathrm{II}}$ Enio Marchesan ${ }^{\mathrm{IV}}$ \\ Edinalvo Rabaioli Camargov ${ }^{\mathrm{V}}$ Walkyria Bueno Scivittaro $^{\mathrm{VI}}$
}

\section{RESUMO}

O clorofilômetro e a cartela de cores têm sido utilizados para monitorar a adubação nitrogenada em diferentes culturas, com o pressuposto de que há uma relação entre suas leituras e o teor de nitrogênio $(N)$ no tecido das plantas. $O$ objetivo deste trabalho foi avaliar a utilização do clorofilômetro e da cartela de cores na estimativa do teor de $\mathrm{N}$ em folhas de arroz irrigado por alagamento. Foram utilizados dois experimentos instalados em um Planossolo Háplico, sendo o primeiro conduzido com cinco doses de $N(0,50,80,120$ e $160 \mathrm{~kg} \mathrm{ha}^{-1}$ na forma de ureia) e a cultivar 'IRGA 417', e o segundo com seis cultivares de arroz irrigado de diferentes ciclos ('BR-IRGA 409', 'BR-IRGA 410', 'IRGA 417', 'IRGA 421', 'EPAGRI 108' $e$ 'HÍBRIDO 2') com uma única dose de $N$. Foram realizadas avaliações com clorofilômetro e a cartela de cores nas folhas do arroz em diferentes épocas. Simultaneamente às leituras, foram coletadas amostras de folhas e nelas determinado o teor de N. Quando variaram as doses de $N$, houve correlação significativa entre as leituras do clorofilômetro e da cartela de cores com o teor de $N$ nas folhas, independente da época de avaliação. Já quando variaram as cultivares, as leituras do clorofilometro se correlacionaram com o teor de $N(r=0,78 ; P<0,05)$, mas não com a cartela de cores ( $r=0,25 n s)$. O clorofilômetro e a cartela de cores foram eficientes para estimar o teor de $N$ quando utilizada uma determinada cultivar, porém, a cartela de cores apresenta maior dependência da interpretação correta do avaliador e uma menor amplitude nas escalas, dificultando, muitas vezes, o melhor ajuste da cor. Quando utilizadas diferentes cultivares de arroz, somente o clorofilômetro é sensível para estimar o teor foliar de $\mathrm{N}$.

Palavras-chave: Oryza sativa, estado nutricional, manejo do $\mathrm{N}$.

\begin{abstract}
The chlorophyll meter and the color chart have been applied to monitor nitrogen fertilization in different crops, based on the assumption that there is a correlation between their readings and the nitrogen content $(N)$ in the plant tissue. This research aims at assessing the use of the chlorophyll meter and the color chart to estimate the $N$ content in leaves of flooded rice plants. Two experiments installed at a Albaqualf (Planossolo Háplico) were used, the first using five $N$ doses $(0,50,80,120$ and $160 \mathrm{~kg} \mathrm{ha}^{-1}$ as urea) and the cultivar 'IRGA 417', and the second with six flooded rice cultivars of different cycles ('BRIRGA 409', 'BR-IRGA 410', 'IRGA 417', 'IRGA 421', 'EPAGRI 108' and 'HÍBRIDO 2') with one only $N$ dose. Assessments with the chlorophyll meter and the color chart were carried out on leaves of rice at different growth stages. Along with the readings, leaves were sampled and the leaf $N$ content was determined. When the $N$ doses varied, there was a meaningful correlation between the readings from the chlorophyll meter and the color chart with the leaf $N$ content, regardless the assessment period. When the cultivars varied, the chlorophyll meter readings correlated with the $N$ content $(r=0.78, P<0.05)$ but not with the color chart ( $r=0.25 n s)$. The chlorophyll meter and the color chart were efficient to estimate the $N$ content when a particular cultivar was used, however, the color chart presents higher dependence of the accurate evaluator's interpretation as well as a narrower range of scales, making it often harder to find the best color setting. When different rice cultivars are used, only the chlorophyll meter is sensitive to estimate the leaf $N$ content.
\end{abstract}

Key words: Oryza sativa, nutritional state, $N$ management.

\footnotetext{
IUniversidade do Oeste de Santa Catarina (UNOESC), Xanxerê, SC, Brasil.

IIDepartamento de Solos, Centro de Ciências Rurais (CCR), Universidade Federal de Santa Maria (UFSM), 97105-900, Santa

Maria, RS, Brasil. E-mail: leandro@smail.ufsm.br. Autor para correspondência.

IIIPrograma de Pós-graduação em Fitossanidade, Universidade Federal de Pelotas (UFPel), Pelotas, RS, Brasil.

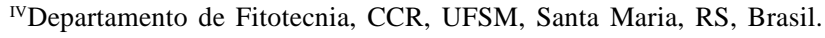

${ }^{v}$ Soil and Crop Science Department, Texas A\&M University, College Station, TX, USA.

${ }^{\mathrm{VI}}$ Empresa de Pesquisa Agropecuária de Clima Temperado (EMBRAPA/CPACT), Pelotas, RS, Brasil.
} 


\section{INTRODUÇÃO}

A lâmina de água aplicada sobre a superfície do solo para a irrigação do arroz (Oryza sativa L.) cria um ambiente de anaerobiose, o qual provoca alterações em algumas propriedades do solo, devido, principalmente, às reações de redução do nitrato, sulfato e óxidos de manganês e de ferro no solo (PONNAMPERUMA, 1972; CAMARGO \& TEDESCO, 2004). De maneira geral, tais reações provocam aumento do $\mathrm{pH}$ e da disponibilidade de vários nutrientes essenciais e a perda de outros, principalmente de $\mathrm{N}$ (SCIVITTARO \& MACHADO, 2004). Entretanto, o manejo da fertilidade para o arroz nas condições de solo alagado é realizado da mesma maneira que cultivos de sequeiro, ou seja, através da análise do solo e consulta de tabelas de recomendação.

A dificuldade de prever a intensidade das transformações que ocorrem com o $\mathrm{N}$, aliada às variações climáticas que controlam a mineralização da matéria orgânica do solo e o crescimento da cultura, tornam os resultados da análise da matéria orgânica do solo seco, antes do cultivo, pouco sensíveis para estimar a disponibilidade de $\mathrm{N}$ às plantas de arroz irrigado após o alagamento (TURNER \& JUND, 1994; SCIVITTARO \& MACHADO, 2004).

Uma possibilidade de complementar a avaliação da disponibilidade de $\mathrm{N}$, estimada pela análise de solo, pode ser realizada através da análise do tecido vegetal, monitorando o estado nutricional das plantas durante o cultivo. Os níveis que indicam a suficiência do teor de $\mathrm{N}$ no tecido, para a cultura do arroz irrigado, são fornecidos pela CQFS RS/SC (2004), para o estádio de florescimento utilizando a folha bandeira. Porém, nessa fase, já não há mais possibilidade de se realizar uma correção da adubação nitrogenada, isso porque a aplicação de $\mathrm{N}$ na fase reprodutiva não aumenta significativamente a produtividade de grãos, uma vez que o número de panículas por área, importante componente da produtividade, é definido na fase vegetativa (FAGERIA \& STONE, 2003). Porém, mesmo a utilização da análise de tecido na fase vegetativa para programar a adubação de cobertura seria limitada pela demora na obtenção dos resultados e pela pouca disponibilidade de laboratórios que realizam este tipo de análise em algumas regiões.

Na busca de procedimentos mais práticos e rápidos para avaliação do estado nutricional das plantas, foram desenvolvidos outros métodos para serem utilizados no campo e que tornam possível a correção deste nutriente durante o ciclo de cultivo. Um dos métodos que já está sendo utilizado em alguns países é o medidor portátil de clorofila (clorofilômetro) modelo SPAD-502 (MINOLTA, 1989). Esse aparelho fornece leituras (unidades $S P A D$ ) que correspondem ao teor do pigmento presente na folha e tem sido utilizado para estimar o teor foliar de $\mathrm{N}$, visto que clorofila e N se correlacionam positivamente na mesma cultura. Para a cultura do arroz, TURNER \& JUND (1991) e PENG et al. (1993) encontraram correlação positiva entre a leitura do clorofilômetro e teor de $\mathrm{N}$ no tecido. Entretanto, a leitura do clorofilômetro pode variar com o estádio de desenvolvimento da planta e entre cultivares, requerendo calibrações individuais entre as leituras obtidas pelo clorofilômetro e o teor de $\mathrm{N}$ no tecido (PENG et al., 1993). Essa ferramenta para a cultura do arroz em nível de Brasil e/ou Rio Grande do Sul ainda é pouco estudada e não se conhecem valores de leituras críticas para a cultura e o comportamento com as cultivares aqui utilizadas.

Adicionalmente, o alto custo do clorofilômetro pode ser uma dificuldade encontrada por muitos produtores e, dessa forma, uma alternativa mais econômica seria a cartela de cores (Leaf Color ChartLCC) (IRRI, 1996). Esta consiste de diferentes tonalidades da coloração verde, as quais têm relação com o teor de $\mathrm{N}$ no tecido e objetivam indicar a necessidade desse elemento às culturas. Assim como para o clorofilômetro, a tonalidade da cor crítica na cartela de cores precisa ser determinada para manejar as aplicações de N (SINGH et al., 2002). Entretanto, da mesma forma que o clorofilômetro, também é necessário avaliar a capacidade da cartela de cores para estimar o teor de $\mathrm{N}$ no tecido das plantas.

O objetivo deste trabalho foi avaliar a utilização do clorofilômetro e da cartela de cores na estimativa do teor de $\mathrm{N}$ no tecido de plantas de arroz irrigado por alagamento.

\section{MATERIAL E MÉTODOS}

Neste estudo, foram utilizados dois experimentos instalados na área experimental do Departamento de Fitotecnia da Universidade Federal de Santa Maria (UFSM), município de Santa Maria - RS, no período de novembro de 2005 a março de 2006. O solo do local de instalação do experimento é classificado como Planossolo Háplico Eutrófico arênico (EMBRAPA, 2006). Sua análise química, realizada pelo Laboratório de Análise de Solos da UFSM, apresentou os seguintes resultados para o primeiro e segundo experimento, respectivamente: teor de argila 340 e $230 \mathrm{~g} \mathrm{~kg}^{-1}$; $\mathrm{pH}_{\text {água }}$ 5,7 e 4,9; índice SMP 6,2 e5,6; M.O. 25 e 19g kg-1; P (Melich-1) 9,3 e 7,6mg dm-3 $\mathrm{K}$ (Melich-1) 52mg dm${ }^{-3}$ e $68 \mathrm{mg} \mathrm{dm}^{-3}$; Ca 7,5 e 7,5 $\mathrm{cmol}_{\mathrm{c}}$ $\mathrm{dm}^{-3}$; $\mathrm{Mg}$ 3,0 e 2,3 $\mathrm{cmol}_{\mathrm{c}} \mathrm{dm}^{-3}$ e saturação por bases 75 e 
59\%. O preparo do solo das áreas experimentais foi realizado através de gradagens, com posterior nivelamento da área.

No primeiro experimento, a semeadura do arroz foi realizada no dia 3 de novembro de 2005, sendo utilizado a cultivar 'IRGA 417'. O delineamento experimental utilizado foi o de blocos ao acaso, com quatro repetições. Os tratamentos utilizados foram cinco doses de $\mathrm{N}\left(0,50,80,120\right.$ e $160 \mathrm{~kg}$ de $\left.\mathrm{N} \mathrm{ha}^{-1}\right)$, sendo o total da dose de cada tratamento subdividida em três épocas de aplicação: $1^{\text {a }}$ ) semeadura - 17,5kg de $\mathrm{N} \mathrm{ha}^{-1}$ correspondendo a $350 \mathrm{~kg} \mathrm{ha}^{-1}$ da fórmula $\mathrm{N}-\mathrm{P}_{2} \mathrm{O}_{5}-\mathrm{K}_{2} \mathrm{O} 5$ 20-30; 2a) estádio vegetativo (V4-V5) - metade da dose aplicada em cobertura para cada tratamento; e 3a) estádio de inicio da diferenciação do primórdio floral (R0) - o restante da dose aplicada em cobertura de cada tratamento.

O segundo experimento foi realizado com seis cultivares de arroz irrigado: 'BR-IRGA 409', 'BRIRGA 410', 'IRGA 417', 'IRGA 421', 'EPAGRI 108' e 'HÍBRIDO 2' (IRGA). Esses materiais foram selecionados em função das diferenças de ciclo, variando de superprecoce (IRGA 421, ciclo \pm 100 dias), médio (BR-IRGA 409, ciclo \pm 126 dias; BR-IRGA 410, ciclo \pm 123 dias; IRGA 417, ciclo \pm 115 dias) a longo (EPAGRI 108, ciclo \pm 142 dias). O delineamento experimental utilizado foi o de blocos ao acaso, com quatro repetições. A semeadura foi realizada no dia 13 de novembro de 2005. A adubação consistiu na semeadura, de 12,5, 50 e $75 \mathrm{~kg} \mathrm{ha}^{-1}$ de $\mathrm{N}, \mathrm{P}_{2} \mathrm{O}_{5}$ e $\mathrm{K}_{2} \mathrm{O}$, respectivamente, e, em cobertura de $110 \mathrm{~kg} \mathrm{ha}^{-1} \mathrm{de} \mathrm{N}$, divididos em duas épocas: 1aa aplicação - estádio vegetativo V4 - 60 $\mathrm{kg} \mathrm{ha}^{-1}$ de N (um dia antes da entrada de água na área) e a 2 a aplicação - início da diferenciação do primórdio floral - R0 - $50 \mathrm{~kg} \mathrm{ha}^{-1}$ de N. A fonte de N utilizada para ambos os experimentos foi ureia e para avaliação dos estádios foi utilizada a escala de COUNCE et al. (2000).

No primeiro experimento, foram realizadas quatro avaliações nas plantas de arroz irrigado: $1^{\text {a }}$ avaliação aos 15 dias após a 1aa aplicação de N em cobertura (15DAAN), 2ª avaliação no início da diferenciação do primórdio floral (R0), 3a avaliação aos 15 dias após R0 (15DAR0) e a 4⿳亠口冋 avaliação no florescimento (entre 30-50\% das panículas florescidas, com pelo menos uma espigueta em antese). O índice de clorofila foi obtido pela leitura do aparelho portátil, clorofilômetro (modelo SPAD-502), com uma leitura na posição intermediária da folha, considerando a última folha completamente expandida, em 15 plantas por subparcela, nas quatro épocas de avaliação. A coloração das folhas foi realizada através do contraste cores das plantas de arroz com as tonalidades de cor verde da cartela de cores Leaf Color Chart, produzida pela University of California Cooperative Extension, na porção intermediária da folha, das mesmas 15 plantas por parcela utilizadas para a leitura com clorofilômetro. Para a determinação do teor de $\mathrm{N}$ no tecido vegetal, foram coletadas amostras, para a 1 $1^{\mathrm{a}}$, $2^{\underline{a}}$ e $3^{\underline{a}}$ avaliações, das duas últimas folhas expandidas de 50 plantas e, na 4⿳亠丷厂 avaliação, amostras de 50 folhas bandeira (última folha expandida). Do material vegetal coletado, realizouse a extração e quantificação do teor de $\mathrm{N}$ seguindo o método descrito por TEDESCO et al. (1995).

No segundo experimento, a avaliação do teor de N na planta foi realizada em cinco épocas: $1^{\text {ạ }}$ avaliação - aos 15 dias após a $1^{\underline{a}}$ aplicação de $\mathrm{N}$ em cobertura; $2^{\underline{a}}$ avaliação - 30 dias após a $1^{1}$ aplicação de $\mathrm{N}$ em cobertura; 3a avaliação - no início da diferenciação do primórdio floral (R0); 4⿳亠口冋 avaliação - aos 15 dias após R0; e a 5a avaliação - no florescimento (30-50\% das panículas florescidas, com pelo menos uma espigueta em antese). A partir da 3ª as avaliações seguiram o estádio fenológico de cada cultivar, em função das diferenças de ciclo. As determinações em cada uma das avaliações foram as mesmas realizadas no primeiro experimento.

Realizaram-se análises de correlação simples (Pearson) entre os dados das leituras do clorofilômetro e da cartela de cores com o teor de $\mathrm{N}$ foliar, utilizando o software estatístico SOC NTIA/EMBRAPA (EMBRAPA, 1997).

\section{RESULTADOS E DISCUSSÃO}

No primeiro experimento, houve correlação significativa $(\mathrm{r}=0,81 ; \mathrm{P}<0,05)$ entre as leituras do clorofilômetro e o teor de $\mathrm{N}$ nas últimas folhas das plantas de arroz irrigado, independente da época de avaliação (Figura 1A). O fato de as leituras do clorofilômetro terem sido realizadas na última folha completamente expandida e o teor de $\mathrm{N}$ determinado nas últimas folhas das plantas explica a significância das correlações nessa situação. ARGENTA (2001) observou que, quando correlacionadas as leituras do clorofilômetro e o teor de $\mathrm{N}$ na planta inteira do milho, somente houve correlação significativa $(\mathrm{P}<0,05)$ para o estádio de espigamento. Já quando determinou o teor de $\mathrm{N}$ na mesma folha (ou em uma folha próxima) na qual realizou as leituras do clorofilômetro, obteve correlação significativa para todos os estádios, com exceção da primeira avaliação (estádio de três a quatro folhas completamente desenvolvidas). Em estudo desenvolvido com a cultivar de arroz irrigado 'IR72', PENG et al. (1993) determinaram o teor de N e realizaram leituras com o clorofilômetro na última folha completamente expandida, em três estádios (meio do perfilhamento, início da diferenciação do primórdio floral 


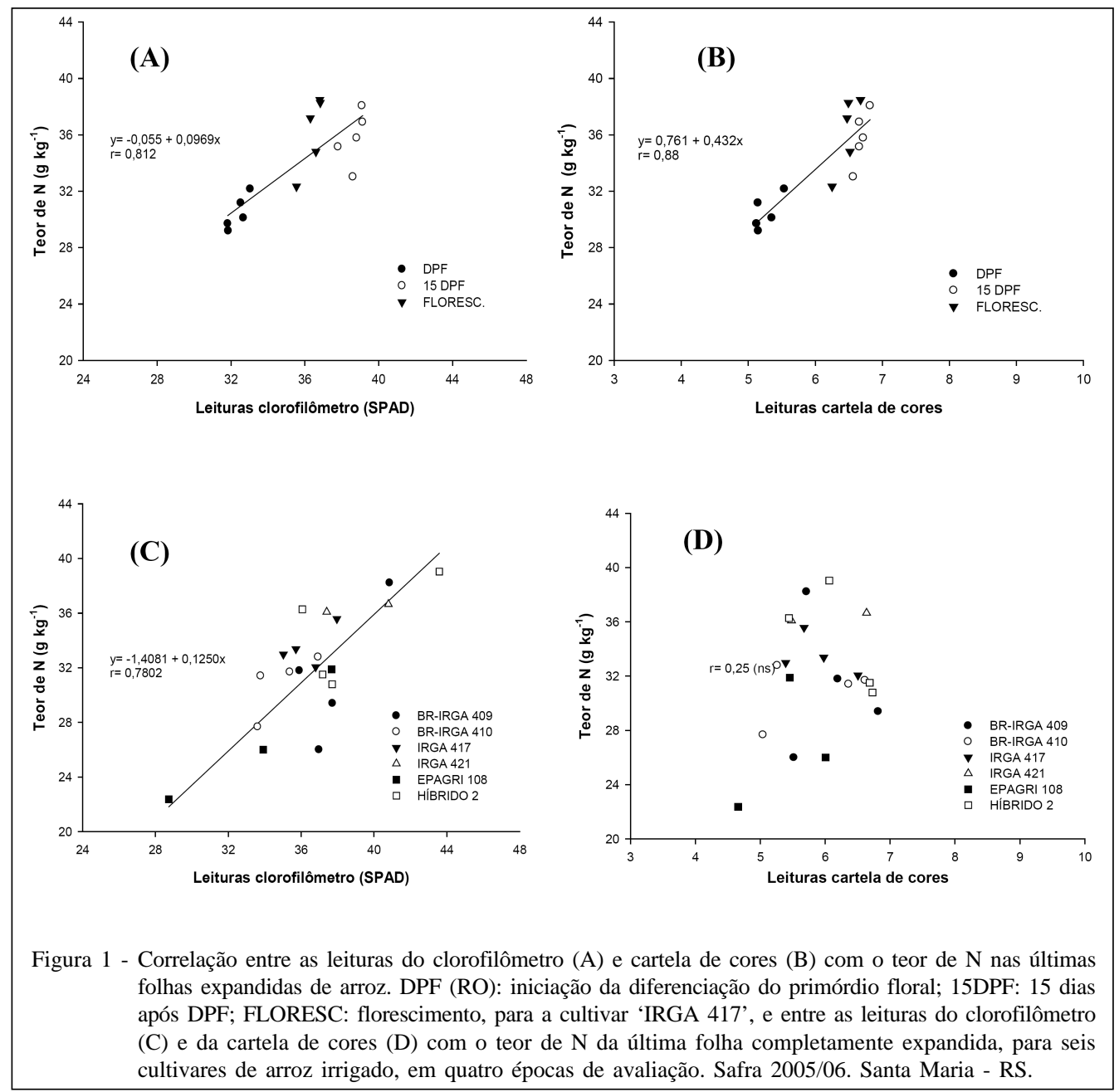

e florescimento), e obtiveram um $\mathrm{R}^{2}=0,49$, o que corresponde a uma correlação (r) de aproximadamente 0,70 , semelhante ao encontrado neste experimento.

A correlação entre as leituras da cartela de cores e o teor de $\mathrm{N}$ nas folhas (Figura 1B) apresentou um comportamento semelhante ao das leituras do clorofilômetro. Nesse caso, a correlação também foi significativa $(r=0,88 ; \mathrm{P}<0,05)$. Entretanto, os valores das leituras realizadas com a cartela de cores tiveram uma amplitude menor do que aquelas obtidas com o clorofilômetro. Isso indica que este método, quando comparado ao clorofilômetro, é menos sensível em diagnosticar as diferenças no teor de $\mathrm{N}$ do tecido vegetal.

Comparando os dois métodos, neste experimento, houve correlação significativa entre o clorofilômetro e a cartela de cores $(r=0,85 ; \mathrm{P}<0,05)$, indicando que, embora com menor sensibilidade para detectar diferenças, como discutido anteriormente, a cartela de cores poderia ser utilizada para substituir o uso do clorofilômetro, caso a precisão não seja um fator importante na avaliação. Entretanto, separando a $1^{\mathrm{a}}$ época de avaliação das demais, o valor (r) para a $1^{\underline{a}}$ época seria de 0,74 e, para as demais épocas, de 0,93, o que indica que a interpretação dos resultados para as avaliações deveria ser separada em função dos estádios (vegetativo e reprodutivo). Cabe salientar que a primeira época de avaliação se diferenciou das demais avaliações, já que houve maior variação nas leituras do clorofilômetro em função das doses de $\mathrm{N}$, sem uma variação proporcional para as leituras com a cartela de cores. Também se deve considerar que a cartela de cores é um método que exige maior interpretação do avaliador, estando sujeita a erros em função do momento de avaliação bem como dos conhecimentos de quem a realiza. Vale lembrar que esse método foi desenvolvido para cultivares utilizadas nos EUA (produzida pela University of California Cooperative Extension) e que a escala de cores pode não ser representativa para as 
cultivares utilizadas nos estados do RS e SC. Assim, embora haja uma indicação potencial de utilização desse método, há que se considerar a interpretação individual neste tipo de avaliação em possíveis recomendações futuras.

No experimento em que se utilizaram diferentes cultivares, as leituras obtidas pelo clorofilômetro apresentaram correlação significativa com o teor foliar de $\mathrm{N}$ para as cultivares testadas (Figura 1C), mesmo ao se considerarem todas as épocas de avaliação conjuntamente. Isso mostra que, independentemente da cultivar ou da época de avaliação, é possível estimar o teor de $\mathrm{N}$ na última folha expandida do arroz por meio da leitura do clorofilômetro. A equação obtida pode ser considerada semelhante à encontrada no experimento anterior. Em estudo com cinco cultivares de arroz irrigado, PENG et al. (1993) encontraram um coeficiente de correlação de 0,71 entre o teor de $\mathrm{N}$ e as leituras do clorofilômetro, semelhante ao encontrado neste experimento $(r=0,78 ; \mathrm{P}<0,05)$. Isso significa que o princípio de avaliação do índice de clorofila é pouco dependente das características das cultivares ou ciclos e possui potencial para estabelecimento de uma única calibração.

Não se observou, porém, significância para a correlação entre as leituras realizadas com a cartela de cores e o teor de $\mathrm{N}$ na folha (Figura 1D). A amplitude restrita da escala de cores e a dificuldade de encontrar correspondência entre as tonalidades de verde disponíveis na cartela e nas cultivares utilizadas, conforme reportado anteriormente, podem ter contribuído para esse resultado. Isso confirma que a cartela de cores não teve a mesma sensibilidade, especialmente na avaliação de diferentes genótipos, em comparação ao clorofilômetro.

Quando comparados os dois métodos, não houve correlação entre as leituras do clorofilômetro e da cartela de cores $(r=0,09 ; n s)$. É plausível que a ausência de correlação da cartela de cores com o teor de $\mathrm{N}$ tenha resultado na ausência de correlação entre os dois métodos também. Isso indica que a cartela de cores não substitui o clorofilômetro indistintamente para diferentes cultivares e épocas de avaliação, o que remete à necessidade de realização de estudos individuais de uso da cartela de cores para determinadas cultivares de arroz irrigado.

Na correlação das leituras do clorofilômetro com a produtividade de grãos, houve correlação significativa somente para o estádio do florescimento no experimento com doses de $\mathrm{N}$ (Figura 2A) e na primeira época de avaliação para o experimento com cultivares (Figura 2C). Esse comportamento pode estar relacionado ao fato de que a avaliação do clorofilômetro em uma única folha não expresse o estado nutricional de toda a planta e de que o fator diluição, provocado pela diferente produção da matéria seca dos cultivares, tenha influenciado na obtenção dos valores do clorofilômetro, não se correlacionando com a produtividade de grãos. Isso também indica que a produção de matéria seca e acúmulo de $\mathrm{N}$ possa ser uma ferramenta importante a se considerar no diagnóstico do estado nutricional das plantas.

A correlação das leituras da cartela de cores com a produtividade de grãos também foi significativa somente para o estádio do florescimento, no experimento de doses de $\mathrm{N}$ (Figura 2B), e não foi significativa para as épocas de avaliação no experimento de cultivares (Figura 2D). Os valores tenderam a diminuir com o aumento da produtividade, o que demonstra falta de aplicabilidade agronômica, tendo em vista que leituras mais altas na cartela de cores, desde que outros fatores não estejam influenciando nas determinações, deveriam refletir melhores condições nutricionais da lavoura e, consequentemente, maiores produtividades.

Assim, pode-se destacar que os resultados obtidos neste trabalho demonstram o potencial de uso, tanto do clorofilômetro quanto da cartela de cores, esta com algumas restrições, para avaliar o teor de $\mathrm{N}$ das plantas de arroz irrigado e, consequentemente, seu estado nutricional. Entretanto, ainda há necessidade de se obter leituras críticas para ambos os métodos, necessitando assim que outros estudos sejam realizados, a fim de determinar valores críticos de leituras do clorofilômetro e/ou cartela de cores, possibilitando futuros ajustes na dose da adubação nitrogenada em cobertura para a cultura do arroz irrigado, em função do estado nutricional das plantas durante o cultivo.

\section{CONCLUSÃO}

Para a cultivar de arroz irrigado 'IRGA 417', tanto clorofilômetro quanto cartela de cores podem ser usados para estimar o teor de $\mathrm{N}$ nas plantas, independente da época de avaliação. Entretanto, o clorofilômetro é mais preciso do que a cartela de cores e esta apresenta maior dependência da interpretação do avaliador e uma menor amplitude nas escalas, dificultando, muitas vezes, o melhor ajuste da cor.

Para diferentes cultivares de arroz irrigado, com diferentes ciclos, apenas o clorofilômetro é sensível para estimar o teor de $\mathrm{N}$ nas plantas, independente da época de avaliação. 

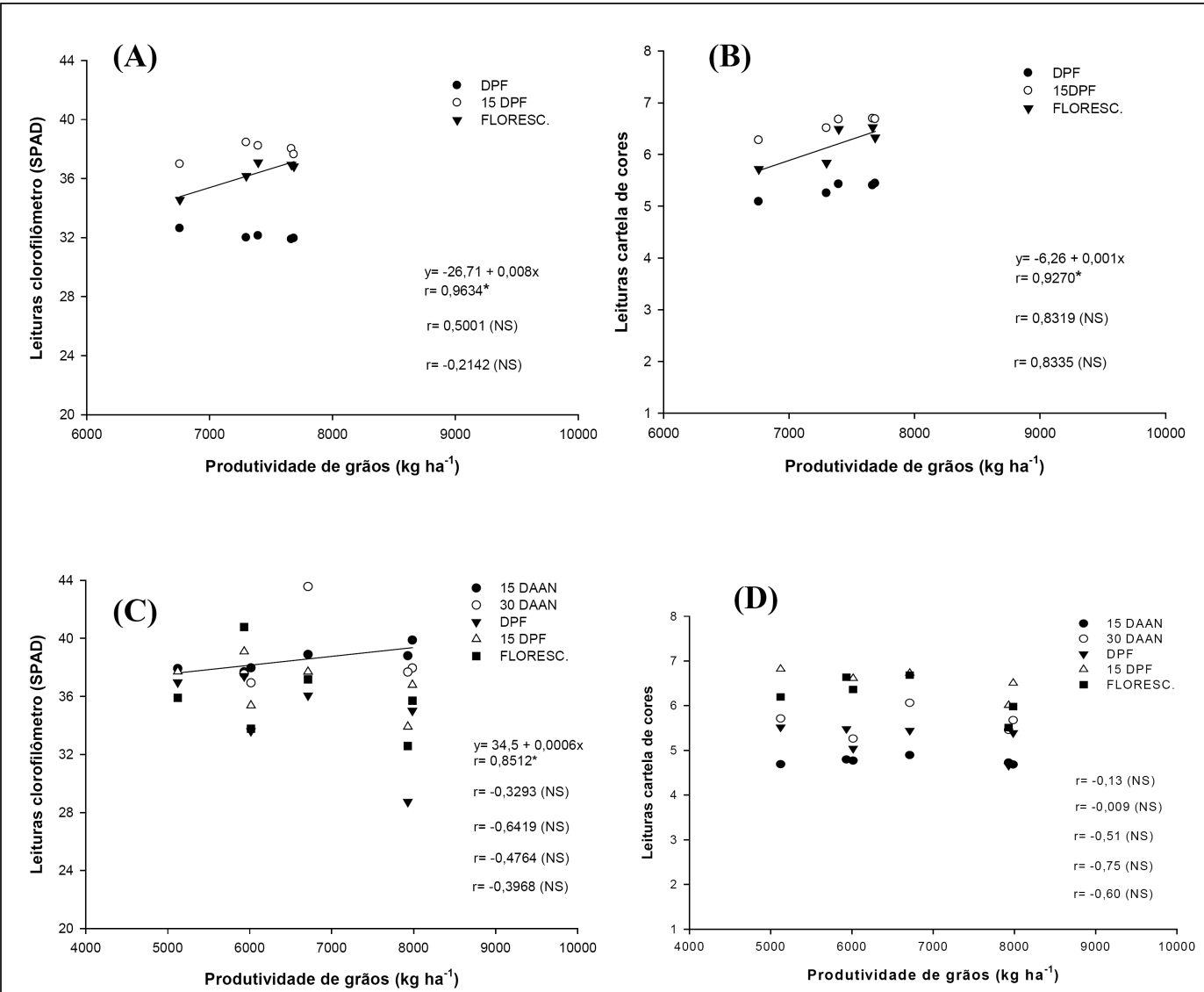

Figura 2 - Correlação entre as leituras do clorofilômetro (A) e da cartela de cores (B) com a produtividade de grãos para três épocas de avaliação, diferenciação do primórdio floral (DPF-RO), 15 dias após a diferenciação do primórdio floral (15DPF) e florescimento (FLORESC.), em função das doses de N, cultivar 'IRGA 417', e entre as leituras do clorofilômetro (C) e a cartela de cores (D) e a produtividade de grãos, aos 15 dias após a $1^{\mathrm{a}}$ aplicação de $\mathrm{N}$ em cobertura (15DAAN), 30 dias após a $1^{\mathrm{a}}$ aplicação de $\mathrm{N}$ em cobertura (30DAAN), DPF, 15DPF e FLORESC, para seis cultivares de arroz irrigado. Safra 2005/06. Santa Maria - RS.

\section{AGRADECIMENTOS}

Ao Instituto Rio-Grandense de Arroz (IRGA), pela concessão das cultivares de arroz irrigado e do clorofilômetro utilizado, à Coordenação de Aperfeiçoamento de Pessoal de Nível Superior (Capes), pela concessão de bolsa de estudos de Mestrado, à Fundação de Amparo à Pesquisa do Estado do Rio Grande do Sul (FAPERGS), pelo auxílio financeiro, e ao Conselho Nacional de Desenvolvimento Científico e Tecnológico (CNPq), pela concessão de bolsa de Iniciação Científica e de Produtividade em Pesquisa.

\section{REFERÊNCIAS}

ARGENTA, G. Monitoramento do nível de nitrogênio na planta como indicador da adubação nitrogenada em milho. 2001. 112f. Tese (Doutorado em Fitotecnia) Universidade Federal do Rio Grande do Sul, Porto Alegre, RS.
CAMARGO, F.A.O.; TEDESCO, M.J. Solos alagados. In: BISSANI, C.A. et al. Fertilidade dos solos e adubação das culturas. Porto Alegre: Gênesis, 2004. 322p.

COMISSÃO DE QUÍMICA E FERTILIDADE DO SOLO - RS/ SC. Manual de adubação e calagem para os Estados do Rio Grande do Sul e Santa Catarina. 10.ed. Porto Alegre: SBCS-Núcleo Regional Sul, 2004. 400p.

COUNCE, P.A. et al. A uniform, objective, and adaptive system for expressing rice development. Crop Science, v.40, n.2, p.436-443, 2000. Disponível em: <http://crop.scijournals.org/ cgi/reprint/40/2/436>. Acesso em: 14 abr. 2010.

EMBRAPA. Centro Nacional de Pesquisa de Solos. Sistema brasileiro de classificação de solos. 2.ed. Rio de Janeiro: Embrapa Solos, 2006. 306p.

EMBRAPA. Ambiente de software NTIA, versão 4.2.2: manual do usuário - ferramental estatístico. Campinas: Centro 
Nacional de Pesquisa Tecnológica em Informática para a Agricultura, 1997. 258p.

FAGERIA, N.K.; STONE, L.F. Manejo do nitrogênio. In: FAGERIA, N.K. et al. Manejo da fertilidade do solo para o arroz irrigado. Santo Antônio de Goiás: EMBRAPA, 2003. 250p.

IRRI. Use of leaf color chart (LCC) for $\mathrm{N}$ management in rice. Crop Resource Management. Network Technology. Brief 2. Los Baños, Laguna, Philippines, 1996. 4p.

MINOLTA CAMERA. Manual for chlorophyll meter SPAD 502. Osaka: Radiometric Instruments divisions, 1989. 22p.

PENG, S. et al. Adjustment for specific leaf weight improves chlorophyll meter's estimate of rice leaf nitrogen concentration. Agronomy Journal, v.85, n.5, p.987-990, 1993.

PONNAMPERUMA, F.N. The chemistry of submerged soils. Advances in Agronomy, v.24, p.29-96, 1972.
SCIVITTARO, W.B.; MACHADO, M.O. Adubação e calagem para a cultura do arroz irrigado. In: GOMES, A. da S.; MAGALHÃES JUNIOR, A.M. de (Org.). Arroz irrigado no sul do Brasil. Brasília-DF: Embrapa, 2004. Cap.9, p.259-303.

SINGH, B. et al. Chlorophyll meter - and leaf color chartbased nitrogen management for rice and wheat in Northwestern India. Agronomy Journal, v.94, p.821-829, 2002.

TEDESCO, J.M. et al. Análise de solos, plantas e outros materiais. Porto Alegre: Departamento de solos, Faculdade de Agronomia. Universidade Federal do Rio Grande do Sul, 1995. 174p.

TURNER, F.T.; JUND, M.F. Chlorophyll meter to predict nitrogen topdress requeriment for semidwarf rice. Agronomy Journal, v.83, n.5, p.926-928, 1991.

TURNER, F.T.; JUND, M.F. Assessing the nitrogen requirements of rice crops with a chlorophyll meter. Australian Journal of Experimental Agriculture, v.34, p.1001-1005, 1994. 